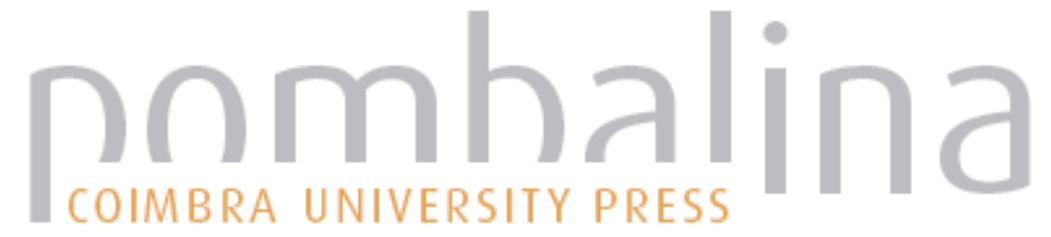

(8)

\section{Transformações e rupturas na ocupação e uso do solo nas serras da cordilheira central}

Autor(es): $\quad$ Fernandes, Gonçalo J. Poeta; Abrantes, Patrícia

Publicado por: Imprensa da Universidade de Coimbra

URL

persistente: URI:http://hdl.handle.net/10316.2/32823

DOI: $\quad$ DOI:http://dx.doi.org/10.14195/978-989-26-0244-8_20

Accessed : $\quad$ 26-Apr-2023 09:07:46

A navegação consulta e descarregamento dos títulos inseridos nas Bibliotecas Digitais UC Digitalis, UC Pombalina e UC Impactum, pressupõem a aceitação plena e sem reservas dos Termos e Condições de Uso destas Bibliotecas Digitais, disponíveis em https://digitalis.uc.pt/pt-pt/termos.

Conforme exposto nos referidos Termos e Condições de Uso, o descarregamento de títulos de acesso restrito requer uma licença válida de autorização devendo o utilizador aceder ao(s) documento(s) a partir de um endereço de IP da instituição detentora da supramencionada licença.

Ao utilizador é apenas permitido o descarregamento para uso pessoal, pelo que o emprego do(s) título(s) descarregado(s) para outro fim, designadamente comercial, carece de autorização do respetivo autor ou editor da obra.

Na medida em que todas as obras da UC Digitalis se encontram protegidas pelo Código do Direito de Autor e Direitos Conexos e demais legislação aplicável, toda a cópia, parcial ou total, deste documento, nos casos em que é legalmente admitida, deverá conter ou fazer-se acompanhar por este aviso.

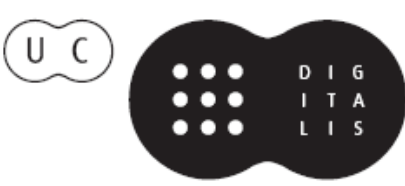




\section{TRUNFOS DE UMA}

\section{EOGRAFIA ACIVA}

\section{DESENVOLVIMENTO LOCAL,}

AMBIENTE,

ORDENAMENTO

E TECNOLOGIA

Norberto Santos

Lúcio Cunha

COORDENAÇÃO 
Gonçalo J. Poeta Fernandes ${ }^{1}$, Patrícia Abrantes ${ }^{2}$

${ }^{1}$ e-Geo - FCSH e ESTH/IPG

${ }^{2} C E G-I G O T$

\section{TRANSFORMAÇÓES E RUPTURAS NA OCUPAÇÃO E USO DO SOLO NAS SERRAS DA CORDILHEIRA CENTRAL ${ }^{1}$}

\section{INTRODUÇÃO}

As serras da Cordilheira Central portuguesa (Malcata, Estrela, Gardunha, Alvelos, Moradal, Açor e Lousã) estabelecem em termos de morfologia, ocupação humana e sistemas produtivos, uma ruptura territorial, quer com os espaços adjacentes, quer entre o Norte e Sul do país. Ao longo dos tempos a cordilheira tem sido ocupada de forma diferenciada, o que tem promovido uma evolução complexa das suas funções e usos, originando processo de readaptação das suas comunidades às lógicas económicas do sistema produtivo e orientaçôes de gestáo.

A Cordilheira Central individualiza-se no espaço nacional pelos valores de altitude e contraste morfológico com as áreas adjacentes, apresentando diferenciaçóes territoriais, quer em termos geomorfológicos, climáticos, de ocupação e uso do solo, quer nas formas e densidades de povoamento e estruturas produtivas. Este território tem sofrido, sobretudo desde meados do século passado, transformações nas formas de apropriação e nos modos de vida, que se traduzem na regressáo populacional, declínio das actividades tradicionais e reconfiguração da paisagem, experimentado novas funcionalidades, que originam formas de ocupação do solo distintas das tradicionais. $\mathrm{Na}$ sua extensão territorial contempla os concelhos das Nut's da Beira Interior Norte, Serra da Estrela, Cova da Beira, Beira Interior Sul, Pinhal Interior Norte e Pinhal Interior Sul, que apresentam na totalidade ou parte do seu território valores de altitude superior aos 400 metros e estão em ligaçáo directa com as serras identificadas.

Dentro da Cordilheira Central, as áreas protegidas (Parque Natural da Serra da Estrela, Reserva Natural da Serra da Malcata e Paisagem Protegida da Serra do Açor) têm registado ocupaçóes e usos diferenciados, em resultado de factores políticos, económicos e sociais que, de modo integrado ou individualmente, lhe imprimem funçóes e valorizaçóes distintas. $\mathrm{O}$ alargamento das manchas florestais e zonas de vegetação arbustiva e herbácea traduzem o recuo do sistema agro-pastoril e a perda de população. A instituição da maior parte das áreas protegidas em Portugal tem-se pautado por uma lógica conservacionista, que tende a valorizar o ambiente e a implementação de uma concepção patrimonial do território, condicionando as actividades estabelecidas pelas suas comunidades.

\footnotetext{
${ }^{1}$ Elaborado no âmbito do projecto "Territorial Cohesion in Portugal: new insights for spatial planning", apoiado pelo Programa Plurianual de Financiamento da Fundaçáo para a Ciência e a Tecnologia.
} 
Para uma leitura das dinâmicas de ocupação do solo na cordilheira central, propôs-se uma metodologia de análise e quantificação espacial da ocupação e uso do solo com suporte em Sistemas de Informação Geográfica (S.I.G.) O tratamento da base de informação geográfica foi realizado com recurso a imagens do Corine Land Cover para os anos de 1990, 2000 e 2006 permitindo identificar, quantificar e cartografar as tendências de uso do solo ocorridas durante a última década e meia, à escala global, concelhia e das áreas protegidas, e as correspondentes reconfiguraçóes das paisagens destas serras.

\section{AS DINÂMICAS TERRITORIAIS DA CORDILHEIRA CENTRAL E A ESTRUTURAÇÃO DA PAISAGEM}

A estrutura da paisagem na Cordilheira Central é complexa. O conjunto montanhoso está afectado por uma erosão vigorosa, que faz alternar vales e interfluvios, encimados por superfícies de aplanação, com uma interdependência vincada das áreas elevadas com a base. Esta origina uma organização espacial escalonada segundo diferentes níveis, por vezes bem diferenciados, em função da variação em altitude e das condiçóes bioclimáticas, impondo ocupaçóes e modos de vida específicos. O povoamento, disseminado, segue alinhamentos específicos, definidos pelo sopé das montanhas e vales dos principais cursos de água. Estes constituem os canais de ligação e articulação preferencial, entre espaços de montanha e áreas baixas que, face às suas características, representam as áreas de maior ocupação humana.

A partir de meados do século XX regista-se um decréscimo acelerado da população e declínio das actividades tradicionais que vão alterar as formas de ocupaçáo do solo e os modos de vida. Os reflexos desta evolução conduziram a uma perda de identidade e ao emergir de novas vocaçóes e aproveitamentos com incidências económicas, sociais e territoriais distintas. Estas mutaçóes introduzem rupturas na estrutura e nas inter-relaçóes existentes. Nesta dinâmica, o declínio demográfico é um dos indicadores que melhor reflecte este problema, com perdas de residentes superiores a 50\%, o alargamento das áreas florestais e a desarticulação das unidades agrícolas. A percepção das diferenças, em termos de rendimentos, conforto e acesso a serviços, evidenciou os desequilíbrios socioeconómicos e potenciou a mobilidade das populaçóes. Este processo incrementou o envelhecimento demográfico e o desmantelamento do sistema produtivo assente na agricultura e pastorícia.

$\mathrm{Na}$ actualidade a desestruturação socioeconómica mantém-se, dando lugar, em simultâneo, ao surgimento de novas perspectivas de exploraçáo do espaço, com destaque para o turismo, onde é necessário evitar a destruição do rico património natural e histórico-cultural, que constitui a base de referência para a melhoria do nível de vida nestas áreas. A serra da Estrela apresenta diferenciaçóes assinaláveis, em termos de morfologia vegetação e ocupação humana, dando origem a um mosaico diversificado de usos onde se encontram instaladas as principais áreas urbanas da Cordilheira. As serras de transição, Lousã, Açor, Gardunha, Moradal e Malcata (quadro 1), podem ser consideradas como montanhas médias, em função da sua altitude, mas bem individualizadas em relação aos espaços baixos adjacentes. O uso florestal domina e as actividades agrícolas e pecuárias são praticadas de forma extensiva. Os espaços agrícolas vão sendo abandonados, ao ritmo do êxodo rural, progredindo os terrenos incultos e a florestação. 
Quadro 1 - Elementos geográficos das serras da Cordilheira Central em 2001

\begin{tabular}{|l|l|l|l|l|}
\hline Serras & $\begin{array}{l}\text { Concelhos } \\
\text { Montanha }\end{array}$ & Área $(\mathrm{Km} 2)$ & Alt. Máx. $(\mathrm{m})$ & Hab/km2 \\
\hline Malcata & 3 & 1904,7 & 1075 & 15,3 \\
\hline Estrela & 10 & 3108,4 & 1993 & 56,9 \\
\hline Gardunha, Alvelos e Moradal & 5 & 2202,9 & 1227 & 27,6 \\
\hline Lousã e Açor & 10 & 1895,1 & 1339 & 55,1 \\
\hline
\end{tabular}

Fonte: Instituto Nacional de Estatísticas

Numa visão de conjunto, verificamos que a economia tradicional baseada na agricultura, pecuária e silvicultura teve, a partir dos anos cinquenta, grandes dificuldades de sobrevivência. As estruturas agrárias apresentam-se desarticuladas e a continuidade das pequenas parcelas são um obstáculo à revitalização económica, quer por especializaçáo agrícola quer por conversão em unidades de recreio. Em simultâneo, regista-se o alargamento das áreas ocupadas com matos e florestas, a expansão das áreas incultos e pastagens. Refira-se que de 2000 a 2006 a incidência de fogos florestais penalizou fortemente estes espaços reduzindo em cerca de $50 \%$ a sua área florestal, sendo as espécies resinosas as mais afectadas. Globalmente podemos verificar uma ocupação diferenciada do solo, apresentando os concelhos das serras da Estrela e Malcata uma maior ocupação agrícola e extensas áreas com vegetação arbustiva e herbácea. A Sudoeste, os conjuntos territoriais da Gardunha, Alvelos e Moradal, e da Lousã e Açor representam áreas de domínio florestal, onde sobressaem as espécies resinosas, embora haja um alargamento das manchas com floresta mista (c.f. figura 1). Aqui as repercussóes dos fogos foram as mais significativas, levando ao abandono das zonas agrícolas de culturas anuais.

Figura 1 - Ocupação do solo nos concelhos integrantes da Cordilheira Central em 1990, 2000 e 2006
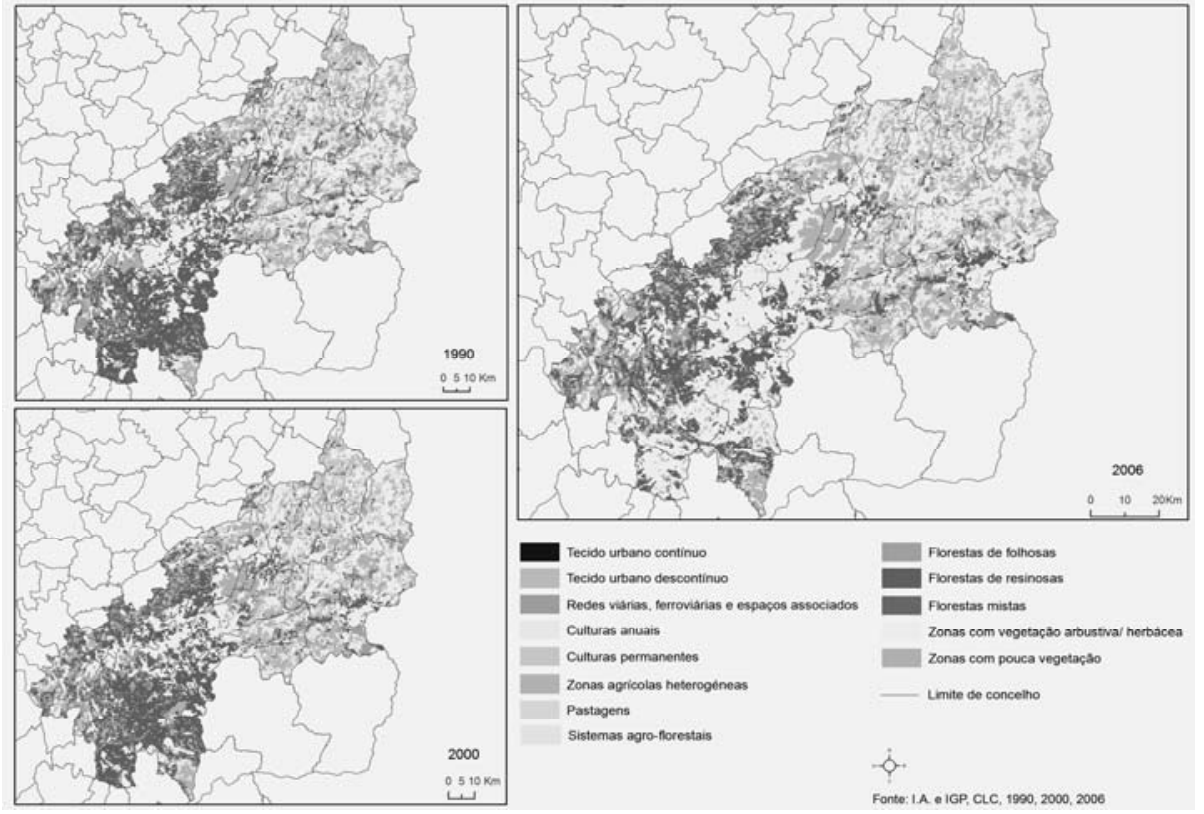
$\mathrm{Na}$ actualidade, verifica-se que as zonas com cobertura arbustiva ou herbácea (421,4 mil ha) e as zonas descobertas sem ou com pouca vegetação (22,5 mil ha), cobrem cerca $48 \%$ do território. Na mancha florestal sobressaem as espécies resinosas $(114,6$ mil ha em 2006), com destaque para o pinheiro bravo, embora registe perdas face à incidência de fogos florestais. As resinosas registam um decréscimo de cerca de 40,5\% desde 1990, tendo desde o inicio deste século registado uma redução de $36,5 \%$ A ocupação agrícola é constituída pelas culturas anuais e por zonas heterogéneas onde se intercalam os espaços agrícolas com os florestais e culturas anuais associadas às permanentes. A desarticulaçáo da base produtiva tradicional, associada às actividades agro-pastoris, conduziu ao alargamento dos incultos e do coberto arbustivo, bem como à expansão de espaços florestais mistos. As zonas agrícolas heterogéneas, com 186 mil ha, correspondente a 19,9\% do total, revelam formas complexas de associação agro-florestal, de caris familiar, com a ocupação de espaços topográficos pouco privilegiados para a sua prática.

Quadro 2 - Ocupação do solo na Cordilheira Central, com base no Corine Land Cover, em 1990, 2000 e 2006

\begin{tabular}{|l|r|r|r|r|r|r|r|}
\hline \multicolumn{1}{|c|}{ Uso do Solo } & \multicolumn{1}{|c|}{1990} & \multicolumn{1}{c|}{2000} & \multicolumn{1}{c|}{2006} & $\begin{array}{r}\text { Var.(ha) } \\
2000-06\end{array}$ & $\begin{array}{r}\text { Var.(ha) } \\
1990-06\end{array}$ & $\begin{array}{r}\text { Var.(\%) } \\
1990-06\end{array}$ & $\begin{array}{r}\text { Var.(\%) } \\
2000-06\end{array}$ \\
\hline Tecido urbano contínuo & 110,1 & 132,0 & 84,4 & $-47,6$ & $-25,7$ & $-23,3$ & $-36,0$ \\
\hline $\begin{array}{l}\text { Tecido urbano } \\
\text { descontínuo }\end{array}$ & 3588,7 & 4505,0 & 7076,3 & 2571,3 & 3487,6 & 97,2 & 57,1 \\
\hline $\begin{array}{l}\text { Áreas agrícolas cl cult. } \\
\text { anuais }\end{array}$ & 51185,6 & 51578,5 & 49229,1 & $-2349,4$ & $-1956,5$ & $-3,8$ & $-4,6$ \\
\hline Culturas permanentes & 27699,2 & 28635,0 & 28684,1 & 49,1 & 985,0 & 3,6 & 0,2 \\
\hline Pastagens & 2774,3 & 2963,5 & 3332,7 & 369,2 & 558,4 & 20,1 & 12,5 \\
\hline $\begin{array}{l}\text { Zonas agrícolas } \\
\text { heterogéneas }\end{array}$ & 190142,6 & 184375,1 & 186029,1 & 1654,1 & $-4113,5$ & $-2,2$ & 0,9 \\
\hline $\begin{array}{l}\text { Territórios agro- } \\
\text { florestais }\end{array}$ & 2070,3 & 2042,6 & 2243,1 & 200,5 & 172,8 & 8,3 & 9,8 \\
\hline Folhosas & 37600,6 & 46596,0 & 42563,5 & $-4032,5$ & 4962,9 & 13,2 & $-8,7$ \\
\hline Resinosas & 192608,7 & 180579,8 & 114608,5 & $-65971,3$ & $-78000,1$ & $-40,5$ & $-36,5$ \\
\hline Floresta mista & 61617,0 & 65852,8 & 57667,3 & $-8185,5$ & $-3949,7$ & $-6,4$ & $-12,4$ \\
\hline $\begin{array}{l}\text { Zonas com floresta } \\
\text { arbustiva ou herbácea }\end{array}$ & 322497,7 & 332812,7 & 421362,3 & 88549,6 & 98864,7 & 30,7 & 26,6 \\
\hline $\begin{array}{l}\text { Zonas descobertas ou } \\
\text { com pouca vegetação }\end{array}$ & 40244,0 & 33464,0 & 22353,1 & $-11110,9$ & $-17890,9$ & $-44,5$ & $-33,2$ \\
\hline
\end{tabular}

Fonte: Corine Land Cover 1990, 2000 e 2006

A progressiva abertura da montanha ao exterior e a manutenção da estrutura económica tradicional ampliam as debilidades e dependência em relação às áreas baixas, reforçando a crise e os desequilíbrios. O crescente relacionamento com as áreas urbanas e a participação de novos agentes modifica gradualmente os comportamentos das comunidades locais e leva à sua reconfiguraçáo económica, demográfica e territorial. O modelo agro-florestal e pastoril, que prevaleceu até à década de 70 , revela-se incapaz de enfrentas os desafios destas áreas, face ao funcionamento actual do mercado, e a sua desarticulação nos usos existentes e nos elementos de suporte físico ao seu funcionamento, ampliam a perda dos modos de vida específicos e a degradação do património ecocultural. 


\section{AS ÁREAS PROTEGIDAS E AS POLÍTICAS DE ORDENAMENTO DO TERRITÓRIO}

A preocupação com a conservação e gestáo das áreas de grande valor natural teve significado no nosso país a partir da década de 60. Contudo, só no início dos anos 70 ocorrem políticas e orientaçóes no sentido da sua preservação, procedendo-se à classificação das áreas mais representativas do património natural. O significado das serras destaca-se na Rede Nacional de Áreas Protegidas, representando cerca de 75\% do total da área classificada. No âmbito da Rede Natura 2000 a expressão destes espaços aproxima-se dos $80 \%$. A instituição da maior parte das áreas protegidas em Portugal tem-se pautado por uma lógica conservacionista, que tende a valorizar o ambiente e a implementação de uma concepçáo patrimonial do território. A maior parte dos espaços protegidos criados em áreas periféricas não conseguiu conter os processos de desertificação humana, social e económica. $\mathrm{O}$ atenuar ou o desaparecimento dos usos tradicionais suporá o desequilíbrio e empobrecimento da vegetação e a destruição de modelos ecoculturais bem enraizados. A frequente descoincidência entre as necessidades globais de protecção da natureza e as necessidades locais de desenvolvimento socioeconómico, pode constituir-se, assim, como um poderoso entrave à gestáo deste tipo de espaços, tal como pode desqualificar a sua percepção e as actividades estabelecidas pelas suas comunidades. Há também a assinalar, como refere SILVA, C. (2000), os conflitos entre os planos de ordenamento das áreas protegidas e os planos locais e regionais de ordenamento, nomeadamente pelas restriçóes de uso impostas, sem um modelo de desenvolvimento estratégico e integrado, que proporcione o incremento da qualidade de vida das comunidades locais.

\subsection{As formas de ocupação e uso das áreas classificadas da Cordilheira}

No conjunto territorial da Cordilheira existem três áreas classificadas como protegidas, de acordo com o Decreto-Lei no 19/93: o Parque Natural da Serra da Estrela(PNSE), a Reserva Natural da Serra da Malcata (RNSM) e a Paisagem Protegida da Serra do Açor (PPSA). Todas são referências internacionais pelas suas particularidades naturais, geomorfológicas e biológico. Os planos de ordenamento que contemplam constituem as referências estruturantes para a sua gestão territorial e enquadramento estratégico. Há ainda a considerar espaços integrados na Rede Natura e Biótipos Corine. Estas áreas apresentam formas de ocupação diferenciadas em função da sua dimensão, da intervenção/apropriação das comunidades locais e das políticas agro-florestais implementados.

Quadro 3 - Ocupação do solo nas áreas classificadas da Cordilheira Central, com base no Corine Land Cover, em 1990, 2000 e 2006

\begin{tabular}{|l|r|r|r|r|r|r|r|}
\hline Uso do solo & 1990 & 2000 & 2006 & $\begin{array}{c}\text { Var (ha) } \\
1990-06\end{array}$ & $\begin{array}{c}\text { Var(ha) } \\
2000-06\end{array}$ & $\begin{array}{c}\text { Var \% } \\
1990-06\end{array}$ & $\begin{array}{c}\text { Var \% } \\
2000-06\end{array}$ \\
\hline Tecido urbano contínuo & 53,2 & 53,2 & 54,9 & 1,7 & 1,7 & 3,2 & 3,2 \\
\hline Tecido urbano descontínuo & 401,7 & 534,2 & 818,9 & 417,3 & 284,7 & 103,9 & 53,3 \\
\hline Áreas agrícolas com cult. anuais & 4407,0 & 4899,4 & 3776,4 & $-630,6$ & $-1123,0$ & $-14,3$ & $-22,9$ \\
\hline Culturas permanentes & 1517,2 & 1758,7 & 1309,3 & $-208,0$ & $-449,5$ & $-13,7$ & $-25,6$ \\
\hline Pastagens & 239,7 & 279,6 & 508,1 & 268,4 & 228,5 & 112,0 & 81,7 \\
\hline Zonas agrícolas heterogéneas & 17545,3 & 16763,4 & 16692,8 & $-852,5$ & $-70,6$ & $-4,9$ & $-0,4$ \\
\hline Territórios agro-florestais & & & & & & & \\
\hline
\end{tabular}




\begin{tabular}{|l|r|r|r|r|r|r|r|}
\hline Folhosas & 2387,9 & 2621,2 & 3785,1 & 1397,2 & 1164,0 & 58,5 & 44,4 \\
\hline Resinosas & 19474,6 & 19173,6 & 14502,9 & $-4971,8$ & $-4670,8$ & $-25,5$ & $-24,4$ \\
\hline Floresta mista & 4207,6 & 4276,1 & 3450,6 & $-757,0$ & $-825,5$ & $-18,0$ & $-19,3$ \\
\hline $\begin{array}{l}\text { Z. com floresta arbustiva ou } \\
\text { herbácea }\end{array}$ & 49865,2 & 50137,1 & 55747,2 & 5882,0 & 5610,2 & 11,8 & 11,2 \\
\hline $\begin{array}{l}\text { Z. descobertas sem ou com } \\
\text { pouca vegetação }\end{array}$ & 16884,9 & 16362,7 & 16151,9 & $-733,0$ & $-210,8$ & $-4,3$ & $-1,3$ \\
\hline
\end{tabular}

Fonte: I.A. CLC. 1990, 2000 e 2006

No seu conjunto representam importantes espaços florestais e de vegetação arbustiva e herbácea, em que matagais, carrascais e pastagens pobres têm uma presença constante e dominante na Malcata e Açor, embora tenha conhecido uma redução significativa, na sequência da florestação dos anos 90 com folhosas no Açor e resinosas na Malcata (Fig. 3). A ocupação agrícola está ausente no Açor, tendo expressão nas outras áreas, especialmente pela presença de culturas anuais e manchas agro-florestais. No PNSE a apropriaçáo humana é mais significativa e o povoamento mais disseminado, com alguns aglomerados com dinâmicas sociais e económicas importantes na estruturação funcional do emprego e prestação de serviços. As zonas agrícolas heterogéneas e a floresta de resinosas correspondem às ocupaçóes mais significativas, contudo verificaram um recuo de $28,7 \%$ e $42,2 \%$, respectivamente desde 1990. No geral verifica-se a diminuição progressiva das áreas agrícolas e o aumento das folhosas e de incultos, como consequências do despovoamento e envelhecimento da população. Saliente-se que esta situação não é desejável do ponto de vista de conservação dos valores paisagísticos e ecológicos, já que as áreas agrícolas assumiam a função de compartimentação das grandes manchas florestais, com efeitos positivos na diminuição do risco de incêndios e no aumento da biodiversidade.

Figura 3 - Variaçóes no uso e ocupação do solo (ha) nas áreas protegidas da Cordilheira Central entre 1990 e 2000.

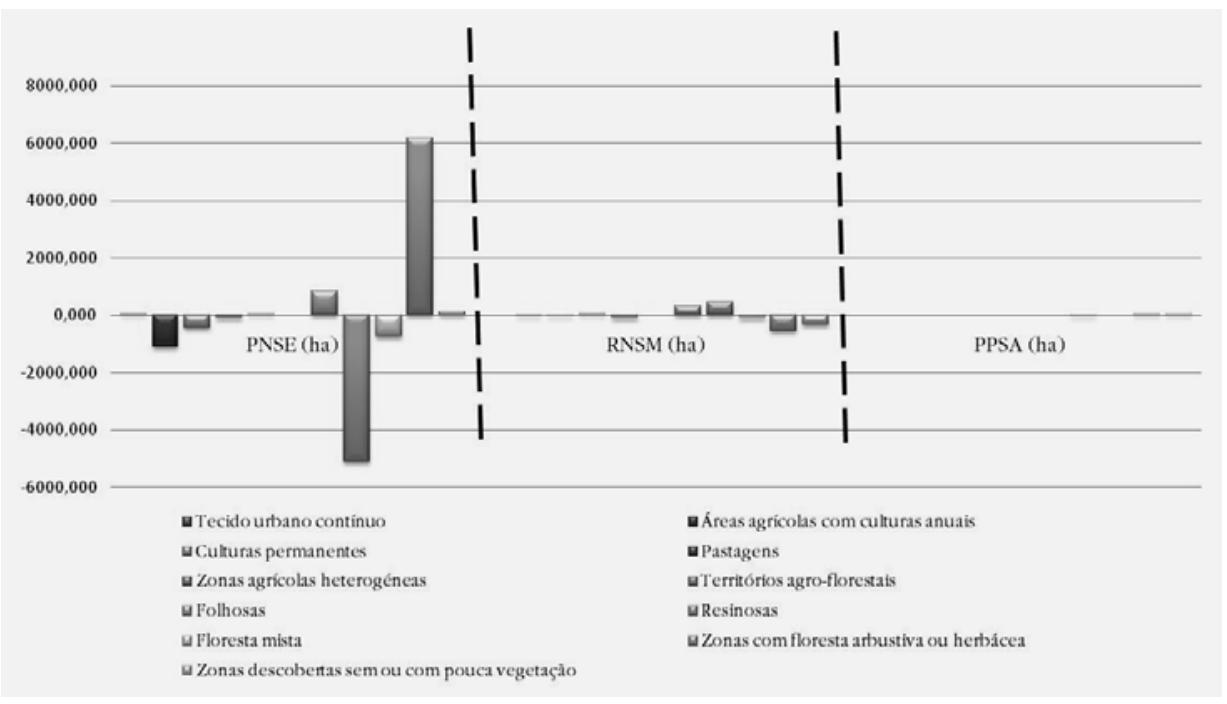


Assim, se o recuo das actividades agrícolas e da densidade populacional é comum a toda a área, a florestação toma especial significado na Malcata, onde a presença humana é reduzida e os interesses associados a industria madeireira, com o alagamento da área ocupada por folhosas contraria a tendência das outras áreas. As zonas com vegetação arbustiva e herbácea revelam decréscimo na RNSM e PPSA, ao contrário do PNSE que verificou desde 2000 um aumento, em cerca de 3245 ha, equivalente a mais $25,7 \%$.

$\mathrm{Na}$ Reserva Natural da Malcata a agricultura de subsistência, ainda praticada, concentra-se maioritariamente junto ao rio Bazágueda, no limite sul, observando-se searas de centeio nas encostas menos declivosas da parte norte da Área Protegida, bem como pequenos olivais e soutos dispersos. Com o abandono das zonas de acesso mais difícil, a mancha florestal aumentou nas últimas décadas, tendo os proprietários privados e os próprios serviços da Reserva, aproveitado os fundo comunitários disponíveis para esse efeito. Como consequência ocorreu um acentuado alastramento da superfície ocupada por espécies exóticas. As zonas de vegetação arbustiva ou herbácea representam 59,3\% da ocupação total da Reserva, tendo-se reduzido em cerca $12,6 \%$ durante a década de 90 , em consequência da florestação encetada com espécies folhosa e principalmente resinosas. Os povoamentos de pinheiro-bravo, pinheiro negro e eucalipto ocupam, em conjunto, mais de um terço da superfície da Área Protegida. Os objectivos prioritários de ordenamento assentam basicamente em três âmbitos: a protecção e recuperação da natureza, em especial as espécies locais mais emblemáticas da área, a intervenção junto dos agricultores e produtores florestais no sentido de adopção de práticas de exploração do solo sustentáveis e a valorização das populaçóes e produçóes locais. Durante a década de 90 a evolução da ocupação do solo na Paisagem protegida da Serra do Açor regista a redução das áreas incultas, cobertas com vegetaçáo arbustiva e herbácea em mais de $32 \%$, e o reforço da floresta, especialmente de folhosas que tiveram um incremento superior a $20 \%$, com destaque para carvalhos e eucaliptos, que se mantém até à actualidade. Na reserva é também significativa a floresta mista, correspondente à associação de várias espécies, das quais se destacam o pinheiro. No conjunto as áreas protegidas assistiram a mudanças nas paisagens como resultado das transformaçóes ocorridas nas estruturas produtiva e organizacional, que concorreram para a perda significativa de população, diminuição das actividades agro-pastoris e alargamento das áreas de floresta e incultos. Esta situação levou ao abandono de extensas áreas agricultadas em torno dos aglomerados populacionais e fundos de vale, à perda de inúmeras estruturas funcionais de apoio às actividades tradicionais - socalcos, muros, caminhos, moinhos e fontes que contribuíram para o policromatismo da paisagem e sua identidade funcional.

\section{CONCLUSÃO}

A Cordilheira Central tem conhecido nas últimas décadas transformação das formas de uso e ocupação do solo, que têm contribuindo para a reconfiguração das paisagens em virtude da desarticulação das estruturas produtivas tradicionais, cujas marcas mais visíveis correspondem ao abandono das parcelas agrícolas, ao alargamento das áreas florestais, muitas das vezes sem respeitar as características e fragilidades dos ecossistemas presente. Assiste-se à perda do valor ecocultura de muitos destes territórios, em que os modos de vida locais não conheceram estímulos à sua perpetuação, a par com o emergir de funçóes, cujas capacidades de valorização destes espaços não têm sido devidamente considerados. As práticas ancestrais de uso sustentável do solo pelas comunidades de montanha tendem a desaparecer e com elas parte da identidade 
cultural destes espaços. A sua gestão tem de reconhecer as especificidades territoriais, e valorizar as comunidades locais como agentes fundamentais para a manutenção das paisagens, face ao desafio e ameaça dos padróes de ocupaçáo das sociedade dominante, promovendo a reterritorializaçáo adulterada destas áreas de montanha. $\mathrm{O}$ valor ecocultural representa uma dimensáo patrimonial capaz de alavancar funçóes e usos que fomentem a sua sustentabilidade, quer nas actividades agro-pastoris, quer nas turísticas. As formas de ocupação e uso das áreas protegidas têm sofrido alteraçóes como resultado do estatuto de gestão a que foram submetidas e das mudanças nas estruturas sócio-produtivas das suas comunidades. Verifica-se um recuo significativo da população que contribui para as mudanças nos modelos produtivos, especialmente nos relacionados com as actividades agrícola. O estabelecimento de planos de ordenamento tem sido conduzido, preferencialmente, por critérios ecológicos que procurando conservar e valorizar os aspectos naturais, ligados à fauna, flora e geomorfologia, não têm conseguido manter os modos de vida das comunidades locais.

\section{REFERÊNCIAS BIBLIOGRÁFICAS}

Aubertin, C. (2001) - "La montagne, um produit du développement durable”, Revue de Geographie Alpine, n², p.102-111, Grenoble.

Cabero Dieguez, V. (1994) - El espacio fronterizo de Salamanca con Portugal. Una aproximacion geográfica y socioeconomica, Universidade de Salamanca, Salamanca.

Cabero Dieguez, V. (1997) - "Los espacios naturales e la valorizacion del paisage como recurso", in Cambios Regionales a finales del siglo XX, Salamanca.

Cravidão, F. e Lourenço, L. (1994). "Cordilheira Central”, Livro-Guia das Excursóes do II Congresso da Geografia Portuguesa, p. 37-62, APG, Coimbra.

Cunha, L. (2003) - "A montanha do centro português: espaço de refúgio, território marginal e recurso para o desenvolvimento local”, in Caetano, L. (Coord.), Território, Ambiente e Trajectórias de Desenvolvimento, Centro de Estudos Geográficos, U. de Coimbra, Coimbra.

Devy-Vareta, N. (2005) - “A floresta na construção das paisagens rurais”, in Geografia de Portugal-Actividades económicas e espaço agrário, p. 115-135, Circulo de Leitores, Lisboa.

DGOTDU - Direcção Geral do Ordenamento do Território e Desenvolvimento Urbano (2004b) - Contributos para a identificação e caracterização da paisagem em Portugal Continental, Volume III, Colecção Estudos 10, DGOTDU, Lisboa.

Fernandes, G. (2005) - "Dinâmicas e transformaçôes nas serras da Cordilheira Ibérica: da (des)articulação produtiva à (re)valorização ecocultural”, in Jacinto, R e Bento, V. (Coord.), Territórios e Culturas Ibéricas, p. 60-74, Campo das Letras, Porto.

Fernandes, G. (2008) - "Perspectivas de desenvolvimento das áreas de montanha. O caso da serra da estrela", in JAcinto, R e Bento, V. (Coord.), O interior raiano do Centro de Portugal. Outras fronteiras, novos intercâmbios, p. 81-100, Centro de Estudos Ibérico, C. das Letras, Porto

Figueiredo, E. (2004) "Proteger o Ambiente em Portugal - De quem, para quem e para quê?" Comunicação apresentada ao $V$ Congresso Português de Sociologia - Sociedades contemporâneas, reflexividade e acção, Universidade do Minho, Braga.

Figueiredo, E. (2007) “A Periferia das Periferias. Áreas protegidas em espaços rurais", in Dentinho, T e RODRIGUES, O. (Coord.), Periferias e Espaços Rurais, II Congresso de Estudos Rurais, p. 151-172, Príncipia Editora, Estoril.

Fischesser, B. (1995) - "La valeur patrimoniale de la montagne", in Barruet, J. Montagne Laboratoire de la diversité, p. 151-157, Cemagref, Grenoble.

Henriques, P.C. (1996) - Parques e Reservas de Portugal, Ed. Verbo, Lisboa.

Lourenço, L. (1995) - Serras de xisto do Centro de Portugal. Contribuição para o seu conhecimento geomorfológico e geo-ecológico, Dissertação de Doutoramento, FLUC, Coimbra.

Silva, C. (2000) - “Áreas Protegidas em Portugal: que papel”, Geoinova, n², p. 27-44, Lisboa.

Veyret, Y. (Coord.), Les montagnes. Discours et enjeux géographiques, p.35-50, SEDES, Vuef. 